\title{
Situation Analysis of Medico-Legal Issues in Asmara, Eritrea, in 2008
}

1Tesfahiwet Gebremariam, ${ }^{2}$ Muluberhan Berhe Hagos

'Orotta School of Medicine, Asmara, Eritrea

PO Box 10549, and ${ }^{2}$ High Court Judge and Legal Researcher, Ministry of Justice Head Office Asmara, Eritrea

E-mail: tefani83@yahoo.com

\section{Abstract}

Background: The Transitional Civil Code of Eritrea (TCCE) enshrines general principles of professional ethics and responsibilities and general principles of ethics have been rendered by training institutions to medical personnel. However, there is serious gap of principles of ethical rules and legislations that serves as binding source governing medico-legal issues in the context of Eritrea.

Objective: The general objective of the Study is to examine the situation of medico-legal issues in Eritrea and to have baseline data about the knowledge, attitude and awareness of the society, health professionals and legal practitioners on medico-legal issues.

Methods: The Study adheres to a structured questionnaire and personal interview with semi-structured checklists developed and administered to respondents to address the socio-demographic data, awareness, attitude, knowledge and practices among randomly selected representatives of health workers, clients and legal practitioners. The Study was done in 3 National Referral Hospitals in Asmara namely, Orotta National Referral Medical Surgical Hospital, Orotta National Referral Maternity Hospital, Berhan Aini Referral Hospital and the High Court and Attorney General's Office.

Results: : A total of 144 respondents were interviewed; 75 clients, 54 health workers and 15 legal practitioners. The most common medico-legal issues identified in the Study are road traffic accidents, rape, homicidal injury and suicide, question of paternity, age determination, abortion, medical record asked by court, insurance, work accident and unknown cause of homicide. The identified medico-legal issues are consistent with the reports from the health personnel and legal practitioners. The health workers know well about their duties and the rights of their patients in rendering medical care. However, they lack the knowledge on the legal basis of their relationship with their clients. Nevertheless, the three hospitals use informed consent in the form of both written and oral forms; $94.1 \%$ in the form of written document and the remaining $5.9 \%$ orally. So far, there are no comprehensively legislated laws or approved detailed rules that govern the relationship of health personnel and the public. Consequently, there have been few medico-legal cases adjudicated before the courts. The few adjudicated cases were raised by the clients against certain members of health personnel.

Conclusion and recommendations: The Study concludes that the knowledge and awareness of the health workers, the public and legal practitioners on medico-legal issues have been gradually increasing. The Study has identified inadequate medical expertise, such as pathologists (post-mortem expertise), psychiatrists and Geneticians (DNA analysis). Furthermore, the Study discovered lack of medical instruments and technical know how to address medicolegal issues, such as paternity and unknown cause of death of human being. The Study, therefore, recommends legislation of public health law that specifically deals with ethical principles, medical professional rights, duties and powers and training of medical expertise specifically on pathology, DNA analysis and psychiatry. Furthermore, the Study recommends inclusion of comprehensive medico-legal curricula in training medical personnel.

\section{Introduction}

The word ethics is derived from the Greek word ethos, which means custom or culture, a manner of acting or constant mode of behavior ${ }^{1}$. Thus, ethics is defined as a systematic or scientific study of morality (of human acts through the medium of natural reason. Medical ethics is a form of special ethics concerned with the application of general principles to the moral problems of the medical profession ${ }^{2}$. It is a fundamental part of life of every one in a society and takes specific form when some one assumes the role of health professional'. Morality is the science concerned with the distinction between right and wrong ${ }^{4}$. A moral act is one which is carried out with at least some degree of knowledge and freedom, proceeding from man's rational nature. A human act which involves some principles of moral law which is in conformity with moral law, is called good but if opposed to moral law, it is called bad. ${ }^{1}$ Medico legal issues can be traced as far back as the prehistoric era when Hippocrates (460$377 \mathrm{BC}$ ) now considered the father of medicine is acclaimed to have said: "I swear by Apollo physician, by Asclepius, by Health, by Heal all and by all the gods and goddesses, making them witness, that I will carry out, according to my ability and judgment, this oath and this indenture. I will use treatment to the sick according to my ability and judgment, but I will never use it to injure or wrong them. I will not give poison to any one though asked to do so, nor will suggest such a plan. Into whatsoever houses I enter, I will do so to help the sick, keeping myself free from all intentional wrong doing and harm, especially from fornication with woman or man, bond or free" ${ }^{1}$.

Medico-legal issues have since evolved and become a complex multi-billion dollar enforceable 
phenomenon worldwide particularly in developed countries. Developing countries are rapidly catching up with global trends in this area especially pertaining to liabilities and litigations. Patient rights, informed consent, malpractice, liability, abortion, euthanasia and harmful cultural believes such as female genital mutilation is attracting attention in developing countries. Medical ethics has common features in different countries. However, each country adopts certain modification according to prevailing local culture, religious beliefs, social norms and standards of medical practice. ${ }^{3,5,6}$

\section{General objective of the study}

The main objective of this study is to examine the Knowledge, Attitudes and Practices on medicolegal issues in the 3 national referral hospitals, High Court and Attorney General's Office that assists in the provision of comprehensive public health law that incorporates ethical principles of medical services in Eritrea..

\section{Methods}

Study Area and Population selection: The selected study areas were three National Referral Hospitals, High Court and Attorney General's Office. They were selected for the following three reasons: First, they are easily accessible due to their proximity to Orrota School of Medicine that I am enrolled with. Second, the three National Referral Hospitals render service to Eritreans from all over the country and ensures the diversity for selecting the sample population. Third, the majority of the cases related to medico-legal issues are framed at the Attorney General's Office and adjudicated at the High Court. The population selection was also done on the following three methods: First, the clients were selected those who attended the out-patient department to the three National Referral Hospitals on random sample bases. Second, the health workers were randomly selected taking Third, the judiciary and the Attorneys were selected due the jurisdiction of the frequently adjudicated medico-legal issues. The Study was done from June 20, 2008 to December 30, 2008.

Sample Size Determination: The sample is designed to get reliable estimate of medicolegal issues by interviewing the clients, health workers, and legal practitioners. The patients were randomly selected during their Outpatient visits in the three National Referral Hospitals. According to Health Management Information System there are approximately 366 Health workers in the three National Referral Hospitals and estimated 42 legal practitioners in the High Court and Attorney General's Office.

Data Collection: It is a descriptive cross-sectional study. A structured questionnaire and semi-structured personal interview was developed and administered to respondents to address the socio-demographic data, awareness, attitude, knowledge and practices among randomly selected representatives sample population. In addition, knowledge of the clients about their rights and health workers on medico-legal issues in each respective hospital was included. The questionnaire that was prepared for the legal practitioners focuses on the common issues adjudicated before the court. The laws that govern medico-legal issues were specifically detailed to solve the cases raised from the alleged victims. The questions were both close and openended. The questionnaire was pre-tested on a few health workers, patients and legal practitioners and was modified according to the obtained feed back

\section{Results}

The total population of the study is: health workers 54, legal practitioners 15, and clients 75. Total: 144

\section{Clients}

Among the interviewed clients 39(52\%) were females and the remaining 36 (48\%) were males. Age range of the respondents was between 15 and 82 years with mean age of 24 and median age of 43 years, respectively. Most of the study group were followers of Orthodox Christian (58.7\%) followed by muslin $24 \%$ and the rest are Catholic Christian and protestant. Forty four percent of the clients were completed primary school, 29\% secondary school, 15\% higher education and the rest $12 \%$ attended middle school. The highest number were from the Tigrinya ethnic group (66.70\%), followed by Saho (12.00\%), the remaining ethnic groups (Tigre, Bilen, Kunama, Nara, Afar) all of them together encompass $21.30 \%$. Most of the clients were housewives by occupation (Figure 1).

Figure 1: Distribution of clients by occupation

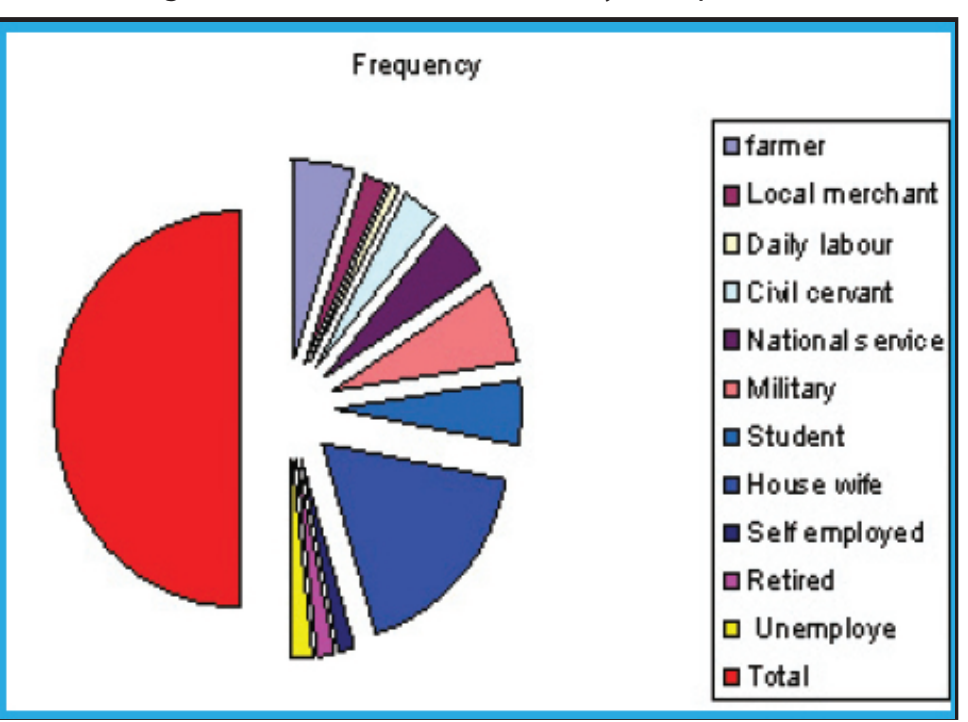

The majority of the respondents in the study group (94.7\%) have never been exposed to situations were the physician do an action without their knowledge. Most of them $(86.70 \%)$ knew that they had the right to medical care. About $81 \%$ of the clients responded that they did not get a chance to see the doctor of their preference. Fifty four clients (74\%) were satisfied the last time they received a prescription for medication.. On the last time they visited the hospital 32(42.7\%) 
responded that they were not given information about the prognosis of their disease that they were expecting from the health institution.

Less than $20 \%$ of the clients had ever been asked to be seen by a doctor of their preference. Three quarters of the clients were satisfied with information provided the last time they received a prescription for medication. Nearly all the clients knew that a patient had a right. Less than $10 \%$ of the clients were exposed to situations where the physician did actions on their bodies without their consent. Nearly forty percent of the clients were not receive information on the prognosis of their diseases.

From the 75 clients only 4 patients (5.33\%) of the total clients interviewed had faced a problem during their visit to the health facility. Three (75\%) did nothing to solve their problem. They left the hospital and moved to another health facility. Only one client asked to the higher authority in the hospital. About $81 \%$ of the clients responded that they did not get a chance to see the doctor of their preference. Reasons given by the clients were, 37 (57.8\%) of them reported, because all the doctors have the same quality, $17.2 \%$ reported that it was immoral and the remaining 16 (25\%) reported, that it was not allowed. Thirty three (45.8\%) of the clients responded that they would ask to Hospital authority in case of any problem happening in the health institution.

\section{Findings from Legal practitioners}

All of the interviewed legal practitioners were from Zoba Maekel. Four (21.40\%) of them were females and 11 were males. Public prosecutors comprised the highest number (60\%) followed by judges (20\%), the remaining $20 \%$ are practicing lawyers (legal consultants) and both practicing lawyers and judges.

Figure2:Distribution of legal practitioners by occupation.

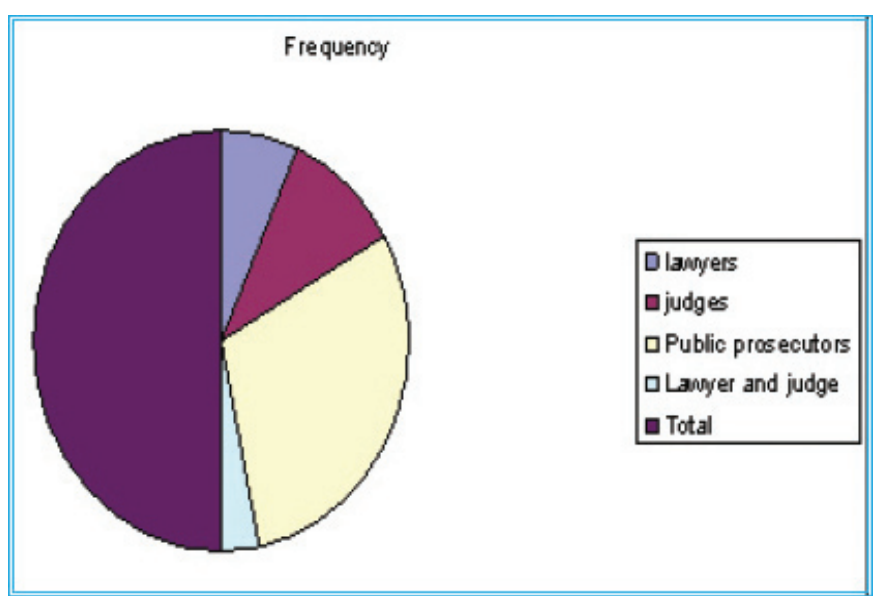

There was no medical expert to entertain the medicolegal issues. They invited medical experts from the medical profession. Eight from the total interviewed legal practitioners were knowledgeable about medical board ethics, but the rest 7 did not have an idea about medical board ethics (Table 1).

\begin{tabular}{|l|c|c|}
\hline \multicolumn{3}{|l|}{ Table 1: Findings from the legal practitioners } \\
\hline $\begin{array}{l}\text { If you are not familiar with } \\
\text { medicine what problems do you } \\
\text { face while entertaining medico } \\
\text { legal cases? }\end{array}$ & Frequency & Percent \\
\hline There is medical expert & 0 & 0.0 \\
\hline Invite medical expert & 15 & 100 \\
\hline Total & 15 & 100.0 \\
\hline $\begin{array}{l}\text { Do you have knowledge about } \\
\text { medical board ethics }\end{array}$ & Frequency & Percent \\
\hline Yes & 8 & 53.33 \\
\hline No & 7 & 46.66 \\
\hline Total & 15 & 100.0 \\
\hline $\begin{array}{l}\text { Do you think medical board ethics } \\
\text { legal issues? }\end{array}$ & Frequency & Percent \\
\hline Yes & 8 & 100.0 \\
\hline No & & 75.0 \\
\hline Total & & 25.0 \\
\hline
\end{tabular}

Findings from Health workers

The majority of the health workers were doctors 16 (29.6\%), midwifes 14 (25.9\%), and 14 Associate nurses (29.6\%) and 10 (18.5\%) were registered and diploma nurses that together encompasses $18.5 \%$

\section{Relationship between the Doctor and nurse}

Thirty six (67.9\%) of the health personals reported that there is good relationship between doctors and nurses. Twenty eight percent explained that the relationship between the Doctors and the nurses are fairly good.

\section{Health workers accused for medical mal practice}

About 8 percent of the health workers were accused for medical malpractice. The remaining $49(92.5 \%)$ never visit to the court due to medical malpractice. This is meant that from 54 health workers, only 5 of them were accused for medical malpractice. The remaining 49 respondents never visited to the court.

About $14 \%$ of health workers were asked to give their expert testimony, among which $92 \%$ of them were doctors. The rest 45 health workers were not asked to give their expertise in their working time. The number of health workers attended to a court hearing of medical malpractice was low, only $18.9 \%$.

The majority of the health workers believe that, the main reason for visiting to the court is being sued followed by as a witness (Figure 3). 
Figure 3: Common reasons for a physician to visit to court

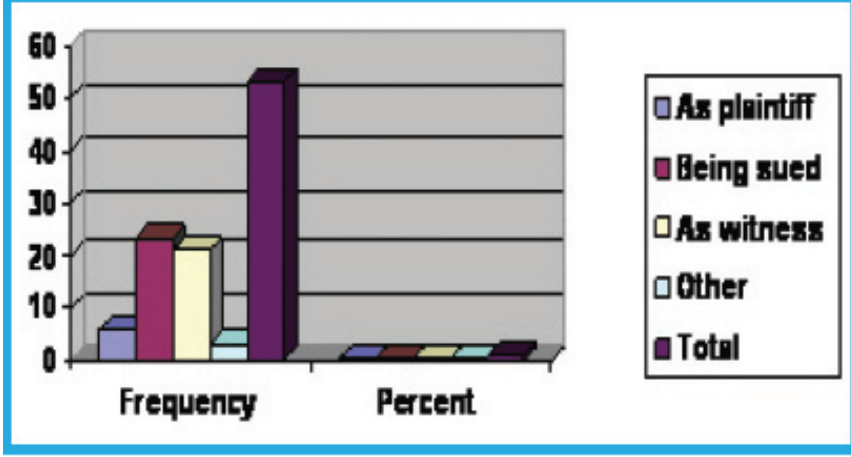

\section{Discussion}

The data was collected by interviewing three categories of respondents, namely clients, health workers, and legal practitioners and was analyzed accordingly. The highest number was from the clients, followed by health workers, then legal practitioners. The common medico legal issues seen in the three respected hospitals are similar. Road traffic accident, rape, homicidal injury, suicide, age determination, abortion, medical record asked by court, insurance, work accident, unknown cause of death. These reports from the health workers are consistent with the data obtained from the legal practitioners concerning the common medico legal issues.

The study revealed that the overall knowledge of the three categories on medico legal issues is satisfactory. Generally speaking, development is at snail speed in many developing countries and supersonic in the developed world and yet these have to interrelate ${ }^{14}$. Studies showed that there is clearly set ethical principles in the developed countries that guide the quality of health care. This is not true in most of the underdeveloped countries. Eritrea is one of the developing countries with out established ethical codes. No principles of ethical codes in the nation. Medical ethics have common features in different counties.

However, each country adopts certain modifications according to prevailing local cultures, religious beliefs, social norms and standards of medical practice.' Therefore, the populations' current beliefs, the standards of the medical practice and religious concepts needs consideration to adopt ethical codes in the nation. The whole idea from this is that the introduction of medical technology and advances into developing countries is warning to be prepared ahead of time to set codes of ethics, because this has the potential to create dilemmas and challenges on the quality of health care. Conflicts can arise with culture, religion and societal norms of both the developed and under developed countries. For example from the 75 clients only 4 patients (5.33\%) of the total clients interviewed have faced a problem during their visit to the health facility. Seventy five percent did nothing to solve their problem. They left the hospital and changed to other health facility. Only one client asked to the higher authority in the hospital.
From this finding, it can be explained in two ways, one, most of the patients didn't have the knowledge whom to ask when they face to challenges in the health institutions and go back home with out feedback and the other thing is, it could be to show human respect. Health worker is well respected. Professional ethics has emerged as the core variable that embodies concepts such as commitment, responsibility, and accountability ${ }^{13}$. This guarantees clinical competency and leads to the application of specialized knowledge and skill by health workers. It has been foundational, at least since Hippocrates, that patients have a right to have personal medical information kept private. Physicians have an obligation to keep medical information secret. The chief public-policy rationale is that patients are unlikely to disclose intimate details that are necessary for their proper medical care to their physicians unless they trust their physicians to keep that information secret ${ }^{17}$. Informed consent is well respected in the three hospitals. It is performed during treatment options, in case of unconscious patient and an unsound mind like children. It has been foundational, at least since Hippocrates that patients have a right to have personal medical information kept private. Physicians have an obligation to keep medical information secret ${ }^{18}$. This is true in our setting.

\section{Legal practitioners}

According to the Transitional Penal Code of Eritrea negligence is defined as the follows "A person is guilty of a criminal negligence:

(a) The offender being aware the consequence of his act but believed on baseless reasons that the consequence would not take place.

(b) The offender failed to foresee the consequence of his act and disregard the foresight of cause illegal and punishable consequences, commits the act regardless that such consequences may follow. A person is guilty of criminal negligence when he fails to take such precautions as might reasonably be expected in the circumstances of the case and having regard to his age, experience, education, occupation and rank.

(2) Offences committed by negligence are liable to punishment only if the law so expressly provides by reason of their nature, gravity or the danger they constitute to society. The Court shall assess sentence according to the degree of guilt and the dangerous character of the offender, and according to his realization of the possible consequences of his act or his failure to appreciate such consequences, as he ought to have done." ${ }^{2}$ Negligence can occur at various stages. A health care provider may misdiagnose a problem, fail to treat the illness properly, prescribing wrong medication, and failure to inform patient about the procedure to be done. The existing Eritrean laws enshrine general principle on professional fault essential to adjudicate cases before court. From the 15 respondents interviewed, all of them, (100\%) responded that the existing Eritrean laws are not sufficient to handle the medico legal cases. The question that can be raised here, are the legal practitioners knowledgeable about the medical practice and can they pick out the problems that 
can happen in the medical profession. As it has been investigated, there is no legal expert in the context of medicine in the country. This also is one deficient that needs to be filled by training. The medico legal issues are governed by the civil, penal, contractual, and extracontractual laws. Physicians revile malpractice claims as random events that visit Unwarranted expense and emotional pain on competent.

In the rapidly changing atmosphere of health care, many factors have affected how health care is practiced. The rights of the patient have also been affected. Patients' rights have recently become the center of national attention in the practice of medicine. The push for legislation of a patients' bill of rights is to provide laws that would prevent health maintenance organizations and other managed health plans from refusing to pay for appropriate care. In the survey done, $13.30 \%$ of the clients said that a patient doesn't have the right to ask and the rest $87.70 \%$ understand about their rights in the medical service. The common reasons raised on why the patient doesn't have the right to refuse Patients rights was first Formalized in 1948, the Universal Declaration of Human rights recognizes "the inherent dignity" and the "equal and unalienable rights of all members of the human family"9.

And it is on the basis of this concept of the person, and the fundamental dignity and equality of all human beings, that the notion of patient rights was developed. "Patients have rights, even when they are in the hospital. Such rights, most centrally, include the right to information (often termed informed consent or informed choice), the right to refuse any treatment, the right to privacy and confidentiality, the right to emergency treatment, and the right to be treated with dignity. ${ }^{13}$ A patient's right to safety could be derived from the fiduciary nature of the doctor-patient relationship. ${ }^{13}$ But physicians do not control all possible risks of injury in the hospital setting. Therefore, it is more appropriate to focus on the hospital and to define the scope of the right to safety as a reflection of corporate responsibility: the obligation of a hospital is to maintain a safe environment for patients and for their health care providers. ${ }^{14}$

\section{Health workers}

The qualitative assessment of their knowledge of the patients' rights, informed consent, and malpractice were seen and the response was fair enough to say that they are well aware of these things. There is good relationship in between the health workers. 36 $(67.9 \%)$ of the health personals reported that there is good relationship between doctors and nurses. 28.3\% explained that the relationship between the Doctors and the nurses are fairly good. 5(7.5\%) of the health workers were accused for medical malpractice. The remaining 49(92.5\%) never visit to the court due to medical malpractice. This means, either the general population is not well aware to ask legally or the culture is a hindrance to go and accuse the health personnel. $13.5 \%$ of health personals were asked to give their expert testimony, among which 92\% from them were doctors. The rest 45 health workers didn't be asked to give their expertise in their working time. The number of health workers attended to a court hearing of medical malpractice was low, only $18.9 \%$ of the interviewed health workers responded yes. More than $80 \%$ did never attend a court hearing of medical malpractice. There are both written and oral forms of informed consent in three of the hospitals. This finding is compatible with the other protocols even in the developed countries. The question here is, are our health personals knowledgeable to perform the consent properly?

The concept of informed consent is derived from respect for the autonomy of the patient and there is general agreement that the consent must be genuinely voluntary ${ }^{1,4}$. Every human being of adult years and sound mind has a right to determine what shall be done with his own body and a surgeon who performs an operation without his patients' consent commits assault. The particular procedures for obtaining voluntary informed consent in developing countries may need to be tailored to local custom and culture, even though we share the view that the principle of informed consent applies throughout the world. ${ }^{19}$ There are two forms of informed consent in the three hospitals namely written form and orally. The survey revealed that the health workers are well aware of the advantages of the consent. Meaning, more than $70 \%$ of the respondents believe that informed consent is advantageous for the hospital, patient and the doctor as well.

\section{Conclusions}

The lack of comprehensive public health law remains serious challenge in addressing medico-legal issues. The legislation of public health law on ethical principle and other related health law would have raised the awareness and knowledge of the public, health workers and legal practitioners on medicolegal issues. Moreover, legislation of public health law could serve as deriving force for training of medical expertise to address medico-legal issues. Furthermore, the concerned organ of the government and nongovernmental bodies would have seriously consider the accessibility and availability technical instruments essential for diagnosing and determining the causes for medico-legal issues.

\section{Recommendations}

The Study suggests the following recommendations:

1. Legislation of Comprehensive Public Health Law is timely and should be set.

2. Training of Medical Expertise Capable of Diagnosing Medico-Legal Issues

3. Including the discipline of Medico-Legal Issues in the Curricula for Training Medical Personnel in any of the medical personnel training institutions

4. Importing Advanced Diagnostic Materials and Machines for Addressing Medico-Legal Issues.

5. Rendering Continuous and Comprehensive Civic Education on Medico-Legal Issues. 
6. Encouraging Further Researches and Investigations on Medico-Legal Issues.

\section{References}

1. Tsehai Gizaw MD, Medical ethics for physicians practicing in Ethiopia, EMPDA; 1987: PP 1-10

2. H. Miles Steven. The Hippocrates oath and the Ethics of medicine Oxford University press; 2004: xiii-xiv.

3. M. Studdert David, LL.B., Sc.D., M.P.H., Mello M Michelle., J.D., Ph.D., Health policy Report; $n$ engl j med 350; 3 www. nejm.org January 15, 2004.

4. 4. Regan Tom, van DeVeer D. Health care Ethics, Philadelphia Temple University; 1987: pp 98-125.

5. 5, Arras J, Hunt R. Ethical issues in Modern Medicine, Mayfield publishing company; 1977: PP 253-264.

6. Elizabeth A. Modern Moral Philosophy, Religion and Politics, Oxford Blackwell; 2002, Vol. 43: pp 345-9.

7. Jonathan ed, Aristotle, Nichomachean Ethics, Princeton University Press; N.J, Princeton, 1984: PP 137-147.

8. Woldu M, LLB. Medical liability in the Eritrean context, Journal of Eritrean medical association, JEMA, volume 1, Number 1, 2006: pp 31-35.

9. Woldu M LLB, Legal advisor, Office of the Minister of Health. Consent statutory provisions in Eritrea, Journal of Eritrean medical association; JEMA, volume 1, Number 1, 2007.

10. The Provisional Government of Eritrea, The Transitional
Penal Code of Eritrea, Journal of Eritrean Laws, Vol.1, No.1, 15 December 1991, article 59, as amended.

11. David M. Studdert, LL.B., Sc.D., M.P.H., Michelle M. Mello, J.D., PhD, Troyen A. Brennan, M.D., J.D., M.P.H. Medical Malpractice; N Engl J Med 350;3 www.nejm.org January 15, 2004.

12. Tribe D, Korgaonkor G. Law for Nurses, Cavendish publishing limited; 1999: pp 25-30.

13. Annas GJ. The rights of patients, New York University Press, 3rd ed; 2004: 452-8.

14. George J. Annas, J.D., M.P.H., The Patient's Right to Safety Improving the Quality of Care through Litigation against Hospitals N Engl J Med 354;19 www.nejm.org, 2006.

15. David M. Studdert, Michelle M. Mello, Troyen A. Brennan. The two cultures: malpractice law and patient safety, Massachusetts Medical Society, N Engl J Med 2004: 350-3.

16. J Prof Nurs. www.nejm.org at Hinari Band on September 25, 2009; 285-91.

17. George J. Annas, J.D., M.P.H. legal issues in medicine (HIPAA Regulations - A New Era of Medical-Record Privacy) Massachusetts Medical Society. N Eng J Med. 2003; 348:

18. Annas GJ. The rights of patients. 2nd ed. Carbondale: Southern Illinois University Press, 1989.

19. Faden R. Jsselmuiden C. Research and informed consent in Africa; N Engl J Med 1992; 326: 830-4. 